\title{
Resíduos Orgânicos Desperdiçados do Setor de Hortifrutigranjeiros em um Supermercado de Caxias do Sul
}

\author{
Wasted Organic Residues from the Horticultural Sector of a Supermarket in the City of \\ Caxias do Sul
}

\author{
Ângela Espíndola*a; Márcia Keller Alves ${ }^{\mathrm{a}}$
}

${ }^{a}$ Faculdade Fátima. RS, Brasil.

*E-mail: angela.espindola@yahoo.com.br.

\begin{abstract}
Resumo
O presente estudo teve como objetivo analisar quantitativa e qualitativamente os resíduos orgânicos desperdiçados do setor de hortifrutigranjeiros de um supermercado na cidade de Caxias do Sul. Para isso, utilizou-se a estrutura do Banco de Alimentos para pesar, separar e destinar à doação somente os resíduos íntegros. O cálculo do percentual das partes comestíveis se deu através do fator de correção, utilizando para os cálculos nutricionais somente o peso líquido. A coleta de 30 dias resultou em 17.047,20 kg de peso bruto de resíduos, com aproveitamento de 27,7\%, sendo $15,55 \%$ provenientes de frutas e $12,18 \%$ de hortaliças. As frutas mais prevalentes foram banana, melancia, tomate e laranja, enquanto as principais hortaliças foram cebola, batata inglesa, batata doce e chuchu. Verificou-se que, se um indivíduo consumisse a quantidade de frutas e verduras recomendada pela Organização Mundial da Saúde, ele seria 100\% atendido em relação ao valor energético, vitamina C e ferro por trinta e dois, vinte e sete e sete anos, respectivamente. O presente estudo mostrou que houve perda de alimentos com grande potencial nutricional, não somente em termos energéticos, mas também de micronutrientes, e que há urgência em projetos e ações que consigam aproveitar um percentual maior de alimentos desperdiçados neste setor.
\end{abstract}

Palavras-chave: Detritos Orgânicos. Reaproveitamento. Desperdício de Alimentos.

\begin{abstract}
The current study aimed to analyze quantitatively and qualitatively the wasted organic residues from the horticultural sector of a supermarket in the city of Caxias do Sul. For this purpose, the structure of the Food Bank was used to weigh, sort and direct to the donation only the whole wast. The percentage of the edible parts was calculated using the correction factor, being used for the nutritional calculations only the net weight. The 30 days of collection resulted in $17,047.20 \mathrm{~kg}$ of gross waste weight, with a $27.7 \%$ harnessing, of which $15.55 \%$ were from fruits and $12.18 \%$ from vegetables. The most prevalent fruits were banana, watermelon, tomato and orange, while the main vegetables were onion, potato, sweet potato and chayote. It was found that if an individual consumed the amount of fruits and vegetables recommended by the World Health Organization, one would be 100\% attended in relation to energy value, vitamin $C$ and iron for thirty-two, twenty-seven and seven years, respectively. The current study showed that there was loss of food with great nutritional potential, not only in energy terms but also in micronutrients, and that there is an urgent need for projects and actions that can take advantage of a greater percentage of wasted food in this sector.
\end{abstract}

Keywords: Organic Debris. Solid Waste Use. Food Wastefulness.

\section{Introdução}

Conforme a Pesquisa Nacional de Amostras por Domicílios (PNAD), a segurança alimentar consiste no acesso regular e permanente a alimentos de qualidade e em quantidade suficiente, sem iminência de sofrer restrição de alimentos em um futuro próximo. No entanto, a pesquisa apontou que 14,7 milhões de domicílios particulares se encontravam em algum grau de insegurança alimentar, sendo 2,1 milhões de domicílios classificados como insegurança alimentar grave (BRASIL, 2014).

Um dos principais desafios relacionados à Segurança Alimentar e Nutricional (SAN) é a criação de um contexto favorável à adoção de hábitos alimentares mais saudáveis e adequados pela população brasileira. A implementação de políticas públicas que promovam uma alimentação adequada e saudável, baseada em alimentos in natura, tem ganhado cada vez mais espaço (BRASIL, 2017). Neste sentido, o consumo de frutas e hortaliças por indivíduos adultos no Brasil, estimado pelo Sistema de Vigilância de Fatores de Risco e Proteção para Doenças Crônicas por Inquérito Telefônico (VIGITEL) aumentou para $35,2 \%$ em 2016, sendo menor em homens (28,8\%) do que em mulheres (40,7\%) (BRASIL, 2017).

A frequência de adultos que consomem cinco ou mais porções diárias de frutas e hortaliças é baixa na maioria das cidades brasileiras, variando entre 15,8\% em Rio Branco e $35,5 \%$ no Distrito Federal (BRASIL, 2017). O baixo consumo regular de frutas e hortaliças faz com que haja um desperdício considerável destes alimentos nos postos de venda, passando a ser chamados de resíduos sólidos orgânicos. Entende-se por resíduo sólido parte dos resíduos gerados que ainda possui valor comercial se for manejado adequadamente, ou seja, só depois de esgotar as possibilidades de utilizar o resíduo de uma atividade para outra é que se pode classificar esse material 
como lixo (BRASIL, 2014). No Brasil, a legislação que trata dos resíduos orgânicos e demais resíduos é a Lei 12.305/2010, Política Nacional de Resíduos Sólidos, a qual abrange todos os tipos de resíduos sólidos e define as diretrizes, princípios e instrumentos fundamentais ao tema (BRASIL, 2010).

De acordo com a Food and Agriculture Organization of the United Nations (FAO, 2013), o desperdício global de alimentos, em 2007, foi estimado em 1,6 bilhões de toneladas, sendo 1,3 bilhões de toneladas de partes comestíveis de alimentos. A maior parte desse desperdício ocorre na produção, pós-colheita e estocagem (54\%), enquanto o menor desperdício ocorre no processamento, distribuição e consumo (46\%). Percebe-se, nesse contexto, a importância do cuidado com o alimento no recebimento, na estocagem e na venda nas redes de distribuição, visto que são etapas que podem contribuir para amenizar a perda por incorreta manipulação.

Considerando o exposto acima, o objetivo da pesquisa foi avaliar os resíduos orgânicos desperdiçados no setor de hortifrutigranjeiros em um supermercado do município de Caxias do Sul-RS, buscando alternativas de reaproveitamento por entidades sociais com vistas à diminuição do desperdício.

\section{Material e Métodos}

Tratou-se da análise quantitativa e qualitativa dos resíduos orgânicos do setor de hortifrutigranjeiros. A coleta de dados foi realizada nas dependências de uma das unidades de uma rede de supermercados localizada na cidade de Caxias do Sul, Rio Grande do Sul e após encaminhada ao Banco de Alimentos da cidade, onde esses resíduos foram selecionados e classificados, ficando apenas os que foram considerados próprios para o consumo.

O processo de seleção e pesagem aconteceu no Banco de Alimentos de Caxias do Sul. A estrutura e balança (marca Mettler Toledo ${ }^{\circledR}$, capacidade $500 \mathrm{~kg}$ ) para realizar a pesquisa foram fornecidas pelo próprio Banco de Alimentos. Verificouse peso bruto e, dos resíduos que puderam ser reaproveitados, o peso líquido, onde foi aplicada a taxa de Fator de Correção Peso Bruto/Peso Líquido. Por fim, os hortifrutigranjeiros selecionados próprios para o consumo, foram doados em conjunto com o planejamento de distribuição do Banco de Alimentos para entidades sociais da cidade.

A análise dos dados foi descritiva e a obtenção da parte qualitativa dos resíduos (nutrientes e energia) sendo calculada em software de nutrição (Avanutri). Os resultados obtidos de peso bruto e peso líquido foram tabulados em planilhas do software Excel, sendo realizado o cálculo da média e desviopadrão da quantidade de resíduos orgânicos encontrados.

Após a obtenção qualitativa dos resíduos, ou seja, a obtenção dos valores em nutrientes e energia, realizou-se a divisão do valor total dos nutrientes e energia pelo valor da Dietary Reference Intakes (DRI) para aquele determinado nutriente e energia. Os valores para esta coluna foram calculados de acordo com a referência para homens adultos de 31 a 50 anos. Com este cálculo, foram obtidos dois valores importantes: 1) o número de indivíduos que poderiam receber aquele nutriente ou energia em um único dia e 2) por quantos dias um único indivíduo receberia aquele nutriente ou energia. No caso dos macronutrientes, padronizou-se em 55, 15 e 30 o percentual de contribuição em carboidratos, proteínas e lipídios para a dieta, respectivamente. Para o cálculo destes valores, considerou-se o peso dos resíduos em gramas.

A densidade energética dos resíduos gerados foi calculada utilizando-se o valor energético divido pelos valores líquidos (em gramas) de frutas e hortaliças obtidas.

\section{Resultados e Discussão}

No período de 30 dias coletou-se o peso bruto de $17.047,20 \mathrm{~kg}$ de resíduos orgânicos provenientes do setor de hortifrutigranjeiros do supermercado. Deste montante, $15,55 \%$ do valor em peso foi de frutas e $12,18 \%$ de hortaliças. Deste modo, percebe-se que o aproveitamento aproximado foi de $27 \%$. No local, circula aproximadamente $2.300 \mathrm{~kg}$ de hortifrutigranjeiros diariamente, sendo que em dias de "feira" (quatro dias por mês) há maior disponibilidade, chegando a $2.500 \mathrm{~kg}$ por dia. No mês da coleta, aproximadamente 70 toneladas de hortifrutigranjeiros circulou no mercado. Segundo dados do local, a "quebra" destes produtos é, em média, cerca de $24 \%$ ao mês. Este resultado corrobora com a publicação do Ministério do Desenvolvimento Social (MDS, 2015), o qual mostra que as Centrais de Abastecimento (CEASA) concentram cerca de $30 \%$ do total de alimentos desperdiçados no país.

O Quadro 1 apresenta as frutas que puderam ser aproveitadas após a seleção dos resíduos. As frutas mais prevalentes (em peso) foram banana, melancia, tomate e laranja, que representaram $50,12 \%$ do peso líquido total de frutas e $28 \%$ do valor de aproveitamento total.

Quadro 1 - Peso líquido (em $\mathrm{kg}$ ) total de frutas, por variedade, gerado durante 30 dias em um supermercado de Caxias do Sul-RS.

\begin{tabular}{|l|c|}
\hline \multicolumn{1}{|c|}{ Frutas } & Peso Líquido \\
\hline Abacate & 28,52 \\
\hline Abacaxi & 45,60 \\
\hline Ameixa vermelha & 9,47 \\
\hline Banana & 462,71 \\
\hline Bergamota/ mexerica & 84,19 \\
\hline Caqui & 74,72 \\
\hline Carambola & 1,00 \\
\hline Coco & 8,64 \\
\hline Goiaba & 134,45 \\
\hline Kiwi & 8,03 \\
\hline Laranja & 239,32 \\
\hline Limão & 114,89 \\
\hline Maçã & 218,25 \\
\hline Mamão & 192,71 \\
\hline Manga & 89,33 \\
\hline Melancia & 383,52 \\
\hline Melão & 100,43 \\
\hline
\end{tabular}




\begin{tabular}{|l|c|}
\hline \multicolumn{1}{|c|}{ Frutas } & Peso Líquido \\
\hline Maracujá & 18,52 \\
\hline Morango & 4,07 \\
\hline Pera & 38,35 \\
\hline Pêssego & 3,89 \\
\hline Pitaya & 19,90 \\
\hline Tomate & 243,46 \\
\hline Uva & 127,38 \\
\hline Total & $\mathbf{2 . 6 5 1 , 3 5}$ \\
\hline
\end{tabular}

Fonte: Dados da pesquisa.

O comportamento do consumidor na hora da compra contribui para o aumento das perdas e do desperdício, pois escolher por muito tempo, manuseando demasiadamente os produtos, contribui para o aumento dos danos físicos, especialmente nas frutas como banana, mamão, manga e tomate (SOARES; JÚNIOR, 2018). Hortaliças e frutas são muito sensíveis ao manuseio, isto é, amassam e rompem a casca com facilidade. Assim, o ideal depois da colheita é o manuseio mínimo de perecíveis, pois quanto menos se manusear hortaliças e frutas, após a colheita, menores as probabilidades de ocorrerem danos mecânicos (LUENGO et al., 2018).

O Quadro 2 apresenta as hortaliças que puderam ser aproveitadas após a seleção dos resíduos. As hortaliças mais prevalentes (em peso) foram cebola, batata inglesa, batata doce e chuchu, que representaram $57,97 \%$ do peso líquido total de hortaliças e $25,46 \%$ do valor de aproveitamento total.

Quadro 2 - Peso líquido (em kg) total de hortaliças, por variedade, gerado durante trinta dias em um supermercado de Caxias do Sul - RS

\begin{tabular}{|l|c|}
\hline \multicolumn{1}{|c|}{ Hortaliças } & Peso Líquido \\
\hline Abobrinha & 68,02 \\
\hline Aipim/mandioca & 71,5 \\
\hline Alface & 74,87 \\
\hline Alho poró & 6,83 \\
\hline Batata doce & 297,42 \\
\hline Batata inglesa & 307,95 \\
\hline Batata yacon & 1,15 \\
\hline Berinjela & 58,91 \\
\hline Beterraba & 57,86 \\
\hline Brócolis & 22,89 \\
\hline Cebola & 329,83 \\
\hline Cebolinha verde & 9,04 \\
\hline Cenoura & 172,2 \\
\hline Chuchu & 268,73 \\
\hline Couve-flor & 22,74 \\
\hline Couve-folha & 6,49 \\
\hline Milho-verde & 25,52 \\
\hline Moranga & 30,36 \\
\hline Pepino & 63,58 \\
\hline Pimentão & 80,39 \\
\hline Repolho & 94,73 \\
\hline Rúcula & 3,22 \\
\hline Vagem & 2,24 \\
\hline Total & $\mathbf{2 0 7 6 , 4 7}$ \\
\hline Pot & \\
\hline
\end{tabular}

Fonte: Dados da pesquisa.
$\mathrm{Na}$ etapa de distribuição de frutas e hortaliças, como é o caso do supermercado, as principais fontes de desperdício são o armazenamento inadequado, falta de treinamento adequado aos funcionários que trabalham nas centrais de abastecimento e nos supermercados quanto ao manuseio dos alimentos e, por fim, os danos causados pelos consumidores finais, principalmente em frutas e hortaliças, que são mais susceptíveis aos danos mecânicos (SOARES; JÚNIOR, 2018).

Os consumidores podem desperdiçar alimentos mesmo sabendo que ainda são apropriados para consumo (PORPINO, 2018). Esta afirmação corrobora com o que foi observado no presente estudo: muitos alimentos encontravam-se apropriados para o consumo, no entanto, eram deixados nas gôndolas e posteriormente descartados, pois culturalmente não estariam íntegros. No primeiro dia de coleta, por exemplo, $40 \mathrm{~kg}$ de bananas totalmente aptos para o consumo foram considerados como quebra de venda por não estarem mais dispostas em cachos: bananas separadas do seu cacho não são compradas pelo consumidor.

Neste contexto, percebe-se que o alto padrão estético exigido pelos varejistas influencia a perda do alimento, pois faz com que os consumidores percebam valor somente nos produtos com formas e tamanhos visualmente perfeitos, impossibilitando a venda de alimentos com aparência diferente da usual (STANGHERLIN, BARCELLOS, 2018).

O Quadro 3 apresenta a distribuição dos nutrientes pelo número de indivíduos e pelo tempo (em dias) possível de uso de cada nutriente, levando em consideração os valores determinados de cada nutriente pela Dietary Reference Intakes (DRI).

Quadro 3 - Distribuição de macro e micronutrientes de resíduos de hortifrutigranjeiros gerados durante trinta dias em um supermercado de Caxias do Sul - RS pelo número de indivíduos e pelo tempo, tendo como referência a DRI.

\begin{tabular}{|l|c|c|c|}
\hline \multicolumn{1}{|c|}{ Nutrientes } & Total & DRI $^{\mathbf{1}}$ & $\begin{array}{c}\mathbf{N}^{\circ} \\
\text { Indivíduos }^{2} \\
\text { ou Tempo }^{3}\end{array}$ \\
\hline Energia (kcal) & $2.714 .670,30$ & 2.000 & $1.357,34$ \\
\hline CHO (kg) & $2.363,65$ & $1,1^{4}$ & $2.148,78$ \\
\hline PTN (kg) & 182,23 & $0,30^{4}$ & 607,45 \\
\hline LIP (kg) & 167,58 & $0,60^{4}$ & 279,31 \\
\hline Retinol (mcg) & $6.685 .749,03$ & 900 & $7.428,61$ \\
\hline Tíamina (mg) & $2.588,12$ & 1,2 & $2.156,77$ \\
\hline Riboflavina (mg) & $1.891,19$ & 1,3 & $1.454,76$ \\
\hline Niacina (mg) & $17.081,61$ & 16 & $1.067,60$ \\
\hline Ácido Pantotênico (mg) & $4.132,34$ & 5 & 826,47 \\
\hline Píridoxina (mg) & $3.038,95$ & 1,3 & $2.337,65$ \\
\hline Ácido Fólico (mcg) & $522.171,35$ & 400 & $1.305,43$ \\
\hline Tocoferol (mg) & 7742,68 & 15 & 516,18 \\
\hline Cobalamina (mcg) & 16,07 & 2,4 & 6,70 \\
\hline Ácido Ascórbico (mg) & $906.925,58$ & 90 & $10.076,95$ \\
\hline Cálcio (mg) & $755.157,1$ & 1.000 & 755,16 \\
\hline Ferro (mg) & $20.722,22$ & 8 & $2.590,28$ \\
\hline Magnésio (mg) & $509.171,55$ & 420 & $1.212,31$ \\
\hline Zinco (mg) & $6.023,96$ & 11 & 547,63 \\
\hline Cobre (mcg) & 2.751 .120 & 900 & $3.056,8$ \\
\hline
\end{tabular}




\begin{tabular}{|l|c|c|c|}
\hline \multicolumn{1}{|c|}{ Nutrientes } & Total & DRI $^{\mathbf{1}}$ & $\begin{array}{c}\mathbf{N}^{\circ} \\
\text { Indivíduos }^{2} \\
\text { ou Tempo }^{3}\end{array}$ \\
\hline Selênio (mcg) & $27.253,54$ & 55 & 495,52 \\
\hline Manganês (mg) & $4.006,09$ & 2,3 & $1.741,78$ \\
\hline Potássio (g) & $8.275,30$ & 4,7 & $1.760,70$ \\
\hline Sódio (g) & 255,72 & 1,3 & 196,71 \\
\hline Fibras (g) & $78.837,35$ & 38 & $2.074,67$ \\
\hline Iodo (mcg) & $44.801,20$ & 150 & 298,67 \\
\hline Fósforo (mg) & $1.005 .665,32$ & 700 & $1.436,66$ \\
\hline
\end{tabular}

${ }^{1}$ Dietary Reference Intakes: os valores para esta coluna foram calculados de acordo com a referência para homens adultos de 31 a 50 anos; ${ }^{2}$ Numero de indivíduos que poderiam ser atendidos, considerando o valor total de nutrientes divididos pela recomendação da DRI; ${ }^{3}$ Número de dias que um indivíduo poderia ser atendido, usando como referência os valores da DRI. ${ }^{4}$ Considerou-se contribuição de $55 \%, 15 \%$ e $30 \%$ para carboidratos, proteínas e lipídios, respectivamente.

Fonte: Dados da pesquisa.

Em relação ao valor energético, verificou-se que um indivíduo poderia receber $2.000 \mathrm{kcal}$ durante $1.357,34$ dias com os alimentos que foram coletados e recuperados. Considerando que um indivíduo deve consumir $400 \mathrm{~g}$ de frutas e verduras por dia, (BRASIL, 2016) e considerando sua densidade energética, calcula-se que este tempo poderia ser ampliado para aproximadamente 11.820 dias. Deste modo, calcula-se que um indivíduo, sozinho, levaria 32 anos para consumir o total líquido dos hortifrutigranjeiros arrecadados.

Os valores de micronutrientes chamam a atenção, pois verifica-se que, para alguns micronutrientes, poder-seiam atender milhares de indivíduos. No caso do potássio, calculou-se que cerca de $1.760,70$ pessoas poderiam receber a quantidade diária recomendada deste micronutriente pela DRI ao consumir os hortifrutigranjeiros que foram descartados pelo supermercado. Outro mineral importante é o ferro. Embora o tipo de ferro encontrado neste tipo de alimento (origem vegetal) não seja absorvido com a mesma eficácia do ferro tipo heme (LEMOS et al., 2012), um único indivíduo teria a quantidade de ferro recomenda pela DRI durante 2.590 dias, aproximadamente.

Os resíduos sólidos orgânicos podem ser reaproveitados através de projetos sociais. Dentre estes, no município de Caxias do Sul, o Banco de Alimentos distribuiu cerca de 70 toneladas de alimentos ao mês. O Quadro 4 mostra a distribuição de macro e micronutrientes potenciais com os alimentos coletados, considerando o número de 7.500 refeições que o Banco de Alimentos referiu no mês de abril de 2018.

Quadro 4 - Distribuição de macro e micronutrientes de resíduos de hortifrutigranjeiros gerados durante trinta dias em um supermercado de Caxias do Sul - RS pelo número refeições oferecidas pelo Banco de Alimentos em um dia

\begin{tabular}{|l|c|c|}
\hline Nutrientes & $\begin{array}{c}\text { Valor Total Do } \\
\text { Nutriente }\end{array}$ & 7.500 Refeições $^{\mathbf{1}}$ \\
\hline Energia $(\mathrm{kcal})$ & $2.714 .670,29$ & 361,95 \\
\hline CHO $(\mathrm{kg})$ & $2.363,65$ & 0,315 \\
\hline PTN $(\mathrm{kg})$ & 182,23 & 0,24 \\
\hline
\end{tabular}

\begin{tabular}{|c|c|c|}
\hline Nutrientes & $\begin{array}{c}\text { Valor Total Do } \\
\text { Nutriente }\end{array}$ & 7.500 Refeições $^{1}$ \\
\hline LIP (kg) & 167,58 & 0,22 \\
\hline Retinol (mcg) & $6.685 .749,03$ & 891,43 \\
\hline Tiamina (mg) & $2.588,12$ & 0,34 \\
\hline Riboflavina (mg) & $1.891,19$ & 0,25 \\
\hline Niacina (mg) & $17.081,61$ & 2,27 \\
\hline $\begin{array}{l}\text { Ácido Pantotênico } \\
\text { (mg) }\end{array}$ & $4.132,34$ & 0,55 \\
\hline Piridoxina (mg) & $3.038,95$ & 0,40 \\
\hline Ácido Fólico (mcg) & $522.171,35$ & 69,62 \\
\hline Tocoferol (mg) & $7.742,68$ & 1,03 \\
\hline Cobalamina (mcg) & 16,07 & 0,00 \\
\hline $\begin{array}{l}\text { Ácido Ascórbico } \\
\text { (mg) }\end{array}$ & $906.925,58$ & 120,92 \\
\hline Cálcio (mg) & $755.157,1$ & 100,68 \\
\hline Ferro (mg) & $20.722,22$ & 2,76 \\
\hline Magnésio (mg) & $509.171,55$ & 67,88 \\
\hline Zinco (mg) & $6.023,96$ & 0,80 \\
\hline Cobre (mcg) & $2.751,12$ & 0,36 \\
\hline Selênio (mcg) & $27.253,54$ & 3,63 \\
\hline Manganês (mg) & $4.006,09$ & 0,53 \\
\hline Potássio (g) & $8.275,30$ & 1,10 \\
\hline Sódio (g) & 255,72 & 0,034 \\
\hline Fibras $(\mathrm{g})$ & $78.837,35$ & 10,51 \\
\hline Iodo (mcg) & $44.801,20$ & 5,97 \\
\hline Fósforo (mg) & $1.005 .665,32$ & 134,08 \\
\hline
\end{tabular}

${ }^{1}$ Número de refeições diárias servidas pelo Banco de Alimentos de Caxias do Sul-RS.

Fonte: Os autores.

A densidade energética dos resíduos obtida no presente estudo foi $0,57 \mathrm{kcal} / \mathrm{g}$. Assim, ao consumir a quantidade recomendada pela OMS de frutas e hortaliças (400 g/dia), o indivíduo deveria receber cerca de $230 \mathrm{kcal}$ somente com estes alimentos. Percebe-se, na Tabela 4, que cada refeição do Banco de Alimentos atenderia a recomendação e ainda excederia o valor em $132 \mathrm{kcal}$. Isso representa, ao final de um mês, $990.000 \mathrm{kcal}$ excedidas em hortifrutigranjeiros. Assim, com o valor excedente, poderiam ainda ser alimentados com estes produtos, aproximadamente, 4.300 indivíduos. Verificase, deste modo, que, se todos os indivíduos recebessem 400 $\mathrm{g} /$ dia de frutas e hortaliças, com o total líquido coletado, poderiam ser alimentados 11.800 indivíduos em um mês.

Portanto, os resíduos encaminhados para descarte representam não somente um desperdício de alimentos, mas também de potenciais nutrientes a indivíduos em insegurança alimentar. Nesse contexto, segundo Raúl Osvaldo Benítez, representante regional da FAO para a América Latina e o Caribe, na venda o país desperdiça 22 bilhões de calorias, o que seria suficiente para satisfazer as necessidades nutricionais de 11 milhões de pessoas e permitiria a redução da fome em níveis inferiores a 5\% (FAO, 2020).

A ausência de ações e políticas específicas que promovam o aproveitamento de alimentos e diminuam o desperdício em toda a cadeia produtiva comprometem a garantia a segurança alimentar e nutricional da população, e consequentemente, o 
direito humano à alimentação, que é direito consagrado na Constituição Federal (BRASIL, 1988; BRASIL, 2006).

Uma das ações quanto à promoção de segurança alimentar, é o Sábado Solidário, que faz a arrecadação de alimentos não perecíveis em 40 mercados parceiros, uma vez por mês, somente no município de Caxias do Sul-RS. Após o recolhimento, esses alimentos são conduzidos a 106 entidades sociais, as quais estão previamente cadastradas. Além disso, o restaurante popular produz refeições visando atender, principalmente, trabalhadores de baixa renda, idosos, desempregados e a população em vulnerabilidade social. Parte do custo com os alimentos é financiado pela Prefeitura Municipal e por empresas parceiras, através da Lei da Solidariedade $n^{\circ} 11853 / 02$, a qual permite financiamento de parte dos custos das refeições, cabendo às pessoas beneficiadas pagar um valor simbólico de R \$1,00 por almoço.

Conforme o Art. $8^{\circ}$ da Lei da Solidariedade, as empresas contribuintes do ICMS que financiarem projetos aprovados pelo Conselho Estadual de Assistência Social, poderão compensar até $100 \%$ do valor comprovadamente aplicado no projeto com o ICMS a recolher por meio de crédito fiscal presumido (BRASIL, 2002).

\section{Conclusão}

O estudo possibilitou avaliar os resíduos desperdiçados vindos do setor hortifrutigranjeiro de uma forma quantitativa e qualitativa, permitindo, assim, uma reflexão ao cenário atual sobre o desperdício de alimentos. Destaca-se a importância desta pesquisa por apresentar resultados que confirmaram o desperdício neste setor. Além dos alimentos que estavam íntegros e que foram encaminhadas as instituições cadastradas pelo banco de alimentos, verificou-se que uma grande quantidade desses hortifrutigranjeiros poderiam ser aproveitados se houvesse estrutura para possibilitar a manipulação dos mesmos a fim de reduzir ainda mais essa perda, criando preparações como geleias, polpas, doces etc. Portanto, o presente estudo serve de incentivo a novas linhas de pesquisas sobre o tema, como, por exemplo, a ampliação da pesquisa sobre resíduos desde o início da cadeia produtiva, podendo se observar as perdas na colheita, transporte, setores atacadistas e até mesmo no consumidor final.

\section{Referências}

BRASIL. Associação Brasileira Das Centrais De Abastecimento - ABRACEN Manual Operacional das CEASAS do Brasil. Gerenciamento dos Resíduos Sólidos nas Centrais de Abastecimento.BeloHorizonte, MG:2014.p. 159-165. Disponível em: http://abracen.org.br/wp-content/uploads/2014/05/manual. pdf.

BRASIL. Câmara Interministerial de Segurança Alimentar e Nutricional. Plano Nacional de Segurança Alimentar e Nutricional - PLANSAN 2016-2019. Brasília, DF: MDSA, CAISAN, 2017.

BRASIL. Presidência da República. Casa Civil. Subchefia para Assuntos Jurídicos. Constituição da República Federativa do Brasil de 1988. Brasília, DF: Senado Federal: Centro
Gráfico, 1988.

BRASIL. Estado do Rio Grande do Sul. Assembleia Legislativa. Gabinete de Consultoria Legislativa. Lei no 11.853, de 29 de novembro de 2002. Institui o Programa de Apoio à Inclusão e Promoção Social e dá outras providências. Disponível em: http://www.al.rs.gov.br/legiscomp/arquivo.asp?Rotulo=Lei\%20 $\mathrm{n} \% \mathrm{BA} \% 2011853 \&$ idNorma $=850 \&$ tipo $=$ pdf.

BRASIL. Ministério da Agricultura, Pecuária e Abastecimento MAPA. Lei $\mathrm{n}^{\circ} 12.305$, de 2 de agosto de 2010. Institui a Política Nacional de Resíduos Sólidos; altera a Lei $\mathrm{n}^{\circ}$ 9.605, de 12 de fevereiro de 1998; e dá outras providências. Disponível em: http://www.planalto.gov.br/ccivil_03/_ato2007-2010/2010/lei/ 112305.htm.

BRASIL. Instituto Brasileiro de Geografia e Estatística - IBGE. Pesquisa Nacional por Amostra de Domicílios Segurança Alimentar. 2014. Disponível em: https://biblioteca.ibge.gov.br/ visualizacao/livros/liv91984.pdf.

BRASIL. Brasil. Ministério da Saúde. Secretaria de Vigilância em Saúde. Departamento de Vigilância de Doenças e Agravos não Transmissíveis e Promoção da Saúde. Vigitel Brasil 2016: vigilância de fatores de risco e proteção para doenças crônicas por inquérito telefônico: estimativas sobre frequência e distribuição sociodemográfica de fatores de risco e proteção para doenças crônicas nas capitais dos 26 estados brasileiros e no Distrito Federal em 2016. Brasília: Ministério da Saúde, 2017. https://portalarquivos.saude.gov.br/images/pdf/2017/junho/07/ vigitel_2016_jun17.pdf.

BRASIL. Ministério do Desenvolvimento Social. Serviço Social do Comércio - SESC Mesa Brasil. Fundação Gaúcha dos Bancos Sociais - Rede de Bancos de Alimentos do Rio Grande do Sul. 2015. Disponível em: http:/www.mds.gov.br/webarquivos/ arquivo/seguranca_alimentar/caisan/RBBA/MINUTA_ Documento_RBBA.pdf.

BRASIL. Presidência da República. Casa Civil. Subchefia para Assuntos Jurídicos. Lei 11.346 de 15 de setembro de 2006. Cria o Sistema Nacional de Segurança Alimentar e Nutricional. Disponível em: http://www4.planalto.gov.br/consea/conferencia/ documentos/lei-de-seguranca-alimentar-e-nutricional.

FAO - Food and Agriculture Organization of the United Nations. Escritório Regional da FAO para a América Latina e o Caribe Notícias: Perdas e desperdícios de alimentos na América Latina e no Caribe. 2020. Disponível em: http://www.fao.org/americas/ notícias/ver/pt/c/239394/.

FAO - Food and Agriculture Organization of the United Nations. Food Wastage Footprint: Impacts on Natural Resources: Summary Report. Editor Food and Agriculture Organization, 2013. Disponível em: http://www.fao.org/3/i3347e/i3347e.pdf.

LEMOS, B.S. et al. Biodisponibilidade de Ferro e a anemia ferropriva na infância. Ensaios Ciênc., v.16, n.4, p.213:228, 2012. doi: https://doi.org/10.17921/1415-6938.2012v16n4p\%25p.

LUENGO, R. et al. Como reduzir o desperdício ao longo da cadeia produtiva de hortaliças e frutas? Contribuição de duas tecnologias Embrapa para campo e distribuição. In: ZARO, M. (Org.). Desperdícios de alimentos: velhos hábitos, novos desafios. Caxias do Sul, RS: EDUCS, 2018.

PORPINO, G. Quais os porquês do desperdício de alimentos entre consumidores? Compreendendo o comportamento do consumidor para delinear soluções. In: ZARO, M. (Org.). Desperdícios de alimentos: velhos hábitos, novos desafios. Caxias do Sul, RS: EDUCS, 2018.

SOARES, A.G.; JÚNIOR, M.F. Perdas de frutas e hortaliças relacionadas às etapas de colheita, transporte e armazenamento. In: ZARO, M. (Org.). Desperdicios de alimentos: velhos hábitos, 
novos desafios. Caxias do Sul, RS: EDUCS, 2018.

STANGHERLIN, I.C.; BARCELlOS, M.D. Desperdício de alimentos: uma análise das diversas variáveis de influência que afetam o consumidor. In: ZARO, M. (Org.). Desperdicios de alimentos: velhos hábitos, novos desafios. Caxias do Sul, RS: EDUCS, 2018. 